\title{
Assessing the Competence of Evidence- Informed Decision-Making Amongst Health Service Managers
}

\author{
Z Liang, P Howard and D Wollersheim
}

\begin{abstract}
Objective: Evidence-informed decision-making (EIDM) amongst health service managers has been positively linked to better decision outcome, hence more effective healthcare provision. Efforts to improve EIDM practice are required to meet the current challenging healthcare environment. One key step to improve such practices is skill enhancement. The purpose of the study is the measure the competence of mid-level managers in two Victorian hospitals in applying EIDM in their roles.
\end{abstract}

Design: The competence of 25 mid-level managers in applying EIDM in their roles was assessed via a $360^{\circ}$ process using an online management competency assessment tool (MCAP Tool) and case-study objective assessment tool.

Setting: Mid-level managers working in Victorian hospitals were selected.

Main outcome measures: The competence of mid-level managers in applying the competency of EIDM was assessed. This paper discusses the areas of improvement identified in enhancing the competence of EIDM amongst mid-level managers in the group, organisational and individual levels.

\section{Zhanming Liang}

School of Public Health and Human Biosciences,

La Trobe University,

Bundoora, Victoria, Australia.

\section{Peter Howard}

College of Science Health and Engineering,

La Trobe University,

Bundoora, Victoria, Australia.

\section{Dennis Wollersheim}

School of Psychology and Public Health,

La Trobe University,

Bundoora, Victoria, Australia.

\section{Correspondence:}

z.liang@latrobe.edu.au
Results: EIDM is an important competency for health service managers. Managers who participated in the assessment are competent in applying EIDM in their roles, but require guidance and improvements. Strengths and weaknesses of managers in applying EIDM in their roles varied between organisations.

Conclusion: This paper suggests that not only improvement of specific aspects of evidenceinformed decision-making amongst health service managers are required, additional more systematic changes at the organisational and individual management level are essential to achieve competent evidence-informed decision-making practices amongst health service managers.

Abbreviations: CCA - Combined Colleagues; CEO Chief Executive Officer; EIDM - Evidence Informed Decision Making; OA - Objective Assessment; SA - Self Assessment.

Key words: evidence-based management/practice; evidence-informed decision-making; health service managers; management competency.

\section{Introduction}

Healthcare has experienced rapid changes in the past two decades and the reform of the healthcare system has altered the ways how it is managed and functions. Recognising the unreliability of decisions made relying solely on experience and motivated by the practice of evidence-based medicine and evidence-based policy, the concept of evidence-based healthcare management has been promoted to maximise the effectiveness and efficiency of service provision by healthcare organisations. $[1,2]$ The most recent literature suggests that evidence-informed decision-making (EIDM) should be one of the core competencies essential to health service managers for effective management performance. 
$[3,4]$ However, recent research suggests that managers may not have absorbed the behaviour into their daily practice, especially the use of scientific evidence to guide decisionmaking. [5,6]

A survey of 130 senior health service managers in Victoria found that own experience, data internally developed in the organisation and stakeholder preference were the three most used evidence types to guide management decisionmaking. [6] Similarly, Birdsell et al found that decision makers' preferred source of knowledge was documents produced within the organisation. [7] Evidence should be broadly defined to include both scientific evidence (the researchers' view) and colloquial evidence (the broader view outside the scientific community). [5] The 'underuse' and 'misuse' of proven management strategies limit management effectiveness. [1]

Factors that influence EIDM amongst managers can be categorised into three levels: societal and industry level (beyond the organisation level), organisational level and individual manager level. [8] One of the barriers at the individual manager level is a lack of skills in searching for, interpreting, appraising and applying health management research findings to practice. [8-11] Investment in the training and development of the competence of health services managers is required. [12] However, before the training and development strategies can be formulated, the current competence of health service managers in applying EIDM in their daily management practice and the associated training needs requires a better understanding.

In this context, competency assessments of midlevel managers in two public hospitals in Victoria were conducted in order to understand managerial competence and competency development needs. [4] The assessment included a $360^{\circ}$ subjective assessment and a case study-based objective assessment, measuring six core competencies confirmed as essential to effective management performance for mid- to senior-level managers in Victoria. [3,4] One of these six core competencies was EIDM.

The purpose of this paper is to present the results of assessment of EIDM in order to answer the following research questions:

1. Are mid-level health service managers competent in demonstrating the competency of EIDM in their roles?

2. Are there behaviours within the competency of EIDM requiring improvement for midlevel health service managers in both individual and organisational levels?

\section{Methods}

\section{Participants}

Invitations to participate in the assessments were sent to Level IV managers in two public hospitals in Victoria, Australia (management level is classified according to the supervision structure with Chief Executive Officers (CEO) as the Level I managers of the organisation). [3,4]

\section{Competence assessment}

Managers' capability in applying EIDM in their roles was tested by a $360^{\circ}$ subjective assessment and a case studybased objective assessment. The $360^{\circ}$ subjective assessment included self-assessment (completed by the primary participating mid-level managers), supervisor assessment, peer assessment (managers from the same management level within the same organisation) and report assessment (staff who report directly to the primary participating managers). It took less than 15 minutes to complete each type of the assessment.

In consideration of how evidence-based management was defined in the literature, [11-14] the study defined evidenceinformed health services management as the systematic application of the best available evidence to decision-making and a process of gathering, assessing and using evidence rather than a simple act of choosing between alternatives. $A$ systematic literature review and intensive consultation with and contribution from management experts from various health services in Victoria and focus group discussions with mid- and senior-level managers resulted in the finalisation of 12 behavioural items (see Appendix I) that constitute the core competency of EIDM. These items were used to test a manager's required level of competence.

The objective assessment was developed as a series of 15 questions related to a case study developed on the planning and implementation of a clinical governance framework across a range of services of a regional health organisation. The questions addressed 11 of the 12 behavioural items related to EIDM listed above (item No.8 omitted). Fifty minutes were allowed for the completion of the assessment. Ten of the items were tested by two multiplechoice questions and one was tested by a single open-ended question.

Assessments were completed online through a web-based platform developed specifically by the research team for hosting and analysing the assessments. To minimise entry error, the assessment process limited the numerical responses to each question and unanswered questions were labelled as missing. Table 1 details the 7-point Likert scale used for the assessment for the level of competency. 
Table 1: Behavioural scale for self-assessment

\begin{tabular}{|c|c|c|}
\hline 1 & Not competent & Do not understand the requirement and am not capable of applying it in my role \\
\hline 2 & Basic or novice & May be capable of demonstrating minor aspects in my role \\
\hline 3 & Advanced beginner & May be capable of demonstrating in my role, but not in all required aspects \\
\hline 4 & $\begin{array}{l}\text { Competent but need } \\
\text { guidance occasionally }\end{array}$ & Can generally demonstrate in my role, but guidance is needed occasionally \\
\hline 5 & $\begin{array}{l}\text { Competent, no } \\
\text { guidance is required }\end{array}$ & $\begin{array}{l}\text { Can generally demonstrate in my role independently, but have not had } \\
\text { extensive experience }\end{array}$ \\
\hline 6 & Proficient & Always apply appropriately in my role, have had extensive experience \\
\hline 7 & $\begin{array}{l}\text { Superior expertise/ } \\
\text { skill coach for others }\end{array}$ & $\begin{array}{l}\text { Always apply appropriately in my role, have had extensive experience and can } \\
\text { teach this competency to others }\end{array}$ \\
\hline
\end{tabular}

\section{Data management and analysis}

Raw data from the server hosting the website were downloaded into MS Excel files for consistency checking and then converted to SPSS (version 22) for further analysis. Univariate analyses for both individuals and groups (management and organisational levels) were also downloaded from the server into MS Excel files for interpretation. The analyses provided separate results for the four subjective assessment types (self, supervisor, peer and report) and the objective assessment. To protect the confidentiality of the colleagues who completed the assessments on the primary participant, mean scores were calculated combining the supervisor, peer and report assessments producing a 'combined colleagues' result. The results are presented as mean scores for each behavioural item (12) and the EIDM core competency. Ethical approval was granted by La Trobe University prior to conducting the project.

\section{Results}

A total of 25 mid-level managers from two public hospitals participated in the $360^{\circ}$ subjective assessments. Seventyeight of their colleagues also participated in the $360^{\circ}$ subjective assessment as assessors. One hospital decided to invite two staff to complete the Report Assessments for each of the primary participating manager. Table 2 details the number of participants in each of the assessments.
Table 2: Participation record for the MCAP assessment

\begin{tabular}{|l|l|c|}
\hline \multirow{3}{*}{$\begin{array}{l}360^{\circ} \text { Subjective } \\
\text { assessment }\end{array}$} & Self-assessment & HOSPITAL \\
\cline { 2 - 3 } & Supervisor assessment & 24 \\
\cline { 2 - 3 } & Peer assessment & 23 \\
\cline { 2 - 3 } & Report assessment & 31 \\
\hline \multicolumn{2}{|l|}{ Objective Assessment } & 18 \\
\hline
\end{tabular}

\section{Competency scores for the mid-level managers}

The vast majority of the managers who completed the $360^{\circ}$ subjective assessments did not skip questions giving a near $100 \%$ completion rate for the 12 behavioural items included to test the EIDM competency. Table 3 shows the mean competency scores calculated from the self- (SA) and combined colleagues (CCA). A mean score of ! 5.0 in the SA and CC assessments indicates that managers can demonstrate such competency independently. The converse is true if the mean scores are less than 5.0. Mean scores less than 4.0 in the objective assessment $(\mathrm{OA})$ also indicate than participants are less then competent. 
Table 3: Competency statistics for evidence-informed decision-making by assessment type

\begin{tabular}{|l|l|c|c|c|}
\hline & MEAN & MEDIAN & MINIMUM & MAXIMUM \\
\hline Self-assessment & $5.13^{*} \#$ & 5.25 & 3.50 & 6.17 \\
\hline Combined colleague assessment & $5.71^{*}$ & 5.69 & 4.14 & 6.65 \\
\hline Objective assessment & $3.59 \#$ & 3.68 & 1.77 & 5.27 \\
\hline
\end{tabular}

${ }^{*} \mathrm{t}=2.939,95 \% \mathrm{Cl}=0.961,0.180, \mathrm{p}=0.005$

$\# \mathrm{t}=4.814,95 \% \mathrm{Cl}=0.871,2.160, \mathrm{p}<0.0005$

Table 4 provides details of mean scores calculated from each of the behavioural items from the SA, CCA and OA. Scores for the individual behavioural items from the different assessments vary considerably. Some items received scores $<5.0$ indicating that occasional support is required for the managers. Behavioural items with scores $<4.0$ indicate that the managers are not yet able to demonstrate the items consistently. The mean scores from the combined colleagues' assessments were consistently higher than those from the selfassessments. The differences between the means were statistically significant when tested by t-tests for all the behavioural items except for one (item 1). In addition, the mean scores from the objective assessments were consistently lower than the self-assessments. The differences between the means were statistically significant when analysed by t-tests for all the behavioural items except three behaviours (items 2, 3 and 4).

Results for managers from the two hospitals were also calculated. Table 5 details the mean scores calculated from each of the behavioural items from the SA as an example.

\section{Strengths and weaknesses of participating managers}

In total, 25 hospital managers participated in the $360^{\circ}$ assessments. Competence levels identified for individual managers varied. In the $360^{\circ}$ subjective assessment, some managers received high mean scores of $\geq 6.0$ from the SA or CCA indicating these managers are not only competent but also have extensive experience in applying EIDM in
Table 4: Mean scores for the 12 behavioural items by assessment type

\begin{tabular}{|l|c|c|c|}
\hline BEHAVIOURAL ITEMS\# & \multicolumn{3}{|c|}{ HOSPITAL MID-LEVEL MANAGERS } \\
\hline & SA & CCA & OA \\
\hline EIDM* MEAN SCORES & 5.13 & 5.71 & 4.42 \\
\hline Item 1 & 5.48 & 5.76 & 4.60 \\
\hline Item 2 & 4.96 & 5.61 & 4.33 \\
\hline Item 3 & 5.12 & 5.63 & 5.70 \\
\hline Item 4 & 5.0 & 5.69 & 6.10 \\
\hline Item 5 & 5.16 & 5.59 & 4.33 \\
\hline Item 6 & 5.24 & 5.81 & 4.20 \\
\hline Item 7 & 4.88 & 5.68 & 4.20 \\
\hline Item 8 & 4.88 & 5.73 & Not \\
\hline Item 9 & 5.22 & 5.54 & 4.0 \\
\hline Item 10 & 5.0 & 5.65 & 3.0 \\
\hline Item 11 & 5.20 & 5.86 & 3.67 \\
\hline Item 12 & 5.39 & 5.9 & 5.57 \\
\hline
\end{tabular}

* Evidence-Informed Decision-Making. Item scores in bold italics indicate low scores.

\# See appendix 1 for a list of item descriptions.

Table 5: Mean scores from self-assessment for managers from two hospitals ( $\mathrm{H} 1$ and $\mathrm{H} 2)$

\begin{tabular}{|c|c|c|c|c|c|c|c|c|c|c|c|c|}
\hline & ITEM 1 & ITEM 2 & ITEM 3 & ITEM 4 & ITEM 5 & ITEM 6 & ITEM 7 & ITEM 8 & ITEM 9 & ITEM 10 & ITEM 11 & ITEM 12 \\
\hline $\mathrm{H} 1$ & 5.57 & 5.57 & 5.51 & 5.29 & 5.71 & 5.71 & 5.0 & 4.86 & 5.43 & 5.0 & 5.71 & 5.71 \\
\hline $\mathrm{H} 2$ & 5.44 & 4.72 & 4.89 & 4.89 & 4.94 & 5.06 & 4.83 & 4.88 & 5.12 & 5.0 & 5.0 & 5.25 \\
\hline
\end{tabular}


Table 6: Percentage of managers with low or high mean scores from the selfassessments, combined colleague assessments and objective-assessments, by organisation.

\begin{tabular}{|l|c|c|c|c|c|c|}
\hline & \multicolumn{2}{|c|}{$\begin{array}{c}\text { \% OF MANAGERS WITH MEAN SCORES }<5.0 \\
\text { FROM SA* \& CCA\# AND MANAGERS WITH MEAN } \\
\text { SCORES <4.0 FROM THE OA^ }\end{array}$} & \multicolumn{3}{c|}{$\begin{array}{c}\text { \% OF MANAGERS WITH MEAN SCORE } \geq 6.0 \\
\text { FROM SA* \& CCA\#, AND \% OF MANAGERS WITH } \\
\text { MEAN SCORES } \geq 5.0 \text { FROM THE OA^ }\end{array}$} \\
\hline & SA & CCA & OA & SA & CCA & OA \\
\hline Hospital 1 & $14 \%$ & $14 \%$ & Not tested & $29 \%$ & $86 \%$ & Not tested \\
\hline Hospital 2 & $39 \%$ & $6 \%$ & 0 & $17 \%$ & $39 \%$ & $12 \%$ \\
\hline
\end{tabular}

* SA = self -assessment; \# CCA = Combined colleagues assessment; $\wedge \mathrm{OA}$ - Objective assessment.

their roles. Conversely, some managers received scores $<5.0$ placing themselves at the bottom of the management group within the organisation. Scores $<5.0$ also indicates that the managers require occasional guidance in applying EIDM in their roles. Table 6 details the percentage of managers who received overall competency mean scores $<5.0$ from either SA or CCA, or who received overall competency mean scores $\geq 6.0$ presented by organisation.

Table 7 details the percentage of behavioural items that have been identified as strengths and weaknesses amongst managers in different organisations. There was large difference between the two hospitals. The participants from Hospital 2 assessed themselves as $50 \%$ of items less than 5.0, indicating 'less than competent', compared to $8 \%$ from hospital 1.

Table 7: Strengths and weaknesses of managers from self-assessment, by organisation.

\begin{tabular}{|l|c|c|}
\hline & HOSPITAL 1 & HOSPITAL 2 \\
\hline $\begin{array}{l}\text { \% of behavioural items with } \\
<5.0 \text { mean score }\end{array}$ & $8 \%$ & $50 \%$ \\
\hline $\begin{array}{l}\text { \% of behavioural items with } \\
\text { mean score } \geq 0.5 \text { above the } \\
\begin{array}{l}\text { competency mean from } \\
\text { self-assessment }\end{array}\end{array}$ & $42 \%$ & 0 \\
\hline
\end{tabular}

\section{Discussion}

Mean scores greater than five received for the overall competency of EIDM from SA and CCA indicate that midlevel managers working in hospitals should be able to apply the competency of EIDM to their roles competently and independently. Not all behavioural items within the competency of EIDM received the same mean scores from the subjective assessment. Items receiving scores significantly lower or higher than the mean of the competency indicate the weaknesses and strengths of the manager in demonstrating the competency. In the CCA, all items received very similar scores within the range of 5.54 and 5.9, which did not assist identifying significant strengths and weaknesses as a group. However, for the SA, items 2, 7 and 8 received scores less than five, indicating some managers require occasional guidance in demonstrating these behavioural items. These items can be seen as perceived weaknesses amongst the managers indicating improvements may be required.

As mentioned earlier, the application of EIDM is not a simple act of choosing from alternative evidence but involves a number of steps reflecting a systematic application of the best available evidence to guide decision-making. [11-14] The study further breaks down such practice into 12 steps demonstrated by 12 behaviours, which can be used to test manager's competence. Therefore, the overall competence of EIDM for the whole management group does not rule out that there are areas that managers can further improve in order to enhance their competence in EIDM. It is believed that the higher the management level, the higher the level of competence expected. [15] The enhancement of the EIDM practices may be essential for management career progression, succession planning and developing the overall management workforce in meeting the diverse needs of the future.

\section{Strengths and weaknesses in EIDM for managers from different organisations}

The literature supports the concept of core competencies amongst specific professions such as health service managers. [15-17] However, the competency contextual sensitivity concept suggests that the level of competence required to demonstrate the core competencies might vary between sectors and organisations. [18] Therefore, the overall competency of the management group may not reflect actual managerial competence from individual organisations. The current study confirms that managers from two different organisations perceived their competence of different behavioural items differently. 
Six out of 12 behavioural items from hospital 2 received mean scores less than five indicating that managers perceived themselves as requiring occasional guidance in demonstrating these behavioural items competently. On the other hand, managers from hospitals 1 gave $42 \%$ items of competency scores of at least 0.5 higher than the overall competency mean from the whole group. These items may indicate that managers in hospital 1 have higher confidence in their competence of demonstrating these particular behavioural items, which can be seen as their strengths.

\section{Competency at the individual manager level}

In total, 103 health service managers participated in the $360^{\circ}$ subjective assessments (at different capacity: primary participants, supervisors, peer and staff). The number of managers perceived as 'requiring guidance in demonstrating the competency of EIDM' and the number of managers perceived as 'highly competent with extensive experience' in the $360^{\circ}$ subjective assessment differs by organisation, as evident in Tables 6 and 7, demonstrating that competence levels identified for individual managers varied significantly across organisations. For example, over a third of managers from Hospital 2 perceived themselves as requiring guidance in applying the competency in their roles, whilst only one manager from Hospital 1 indicated likewise. Conversely, more than four fifths of managers from Hospital 1 were perceived as highly competent by their colleagues. This supports the concept that management competency is context sensitive. Thus, the requirements for enhancing the EIDM competence for a management group at the system level and at the individual or organisation level may be different. $[8,10]$

The study confirms that the requirements for improving managerial competence such as EIDM vary between individual managers. Therefore, in addition to considering strategies at both the system and organisation levels, it is equally important that the needs for the improvement of competence in EIDM amongst individual managers are identified, and that targeted training and development opportunities are provided for the achievement of competency improvement. This supports Liang et al's that factors such as skill requirements are addressed at the individual level in order to improve the overall EIDM competence of the management group. $[8,10]$

\section{Implications to organisations: addressing the organisational level barriers to EIDM}

Despite the speculation in the literature that health service managers may not have the required skills to apply EIDM in their roles, this study strongly suggests that mid-level managers from Victorian hospitals are competent. This again prompts the question of why managers do not apply EIDM in their daily work as discussed in the introduction. Drawing on Liang et al's study, from the eight key barriers to evidence-based management practice identified amongst Victorian mid- to senior-level health service managers, the top ranking factors were: time availability, relevance of management research, and a lack of financial resources to support best practice. [8-10] A lack of critical appraisal skills was ranked eighth on the list. However, the study participants suggested skills that critically appraise evidence as one of the top three factors that could improve and encourage EIDM at the management level. [10] The current study clearly confirmed that, despite the competence demonstrated in the assessment, there are areas in EIDM practice requiring improvement for the whole management group in both hospitals and CHS, for some management groups in individual organisations and for some individual managers. Therefore, a mixture of strategies is required to achieve system level, organisational level and individual management level improvement in the EIDM competence.

Furthermore, at the system and organisational levels, investment in skills enhancement for managers alone may not be adequate in improving and encouraging the EIDM practice. Many other key factors [8] that influence EIDM practice needs to be addressed. Areas include: i) improving the usefulness and relevance of research evidence with actionable recommendations based on contextual consideration; $[19,20]$ ii) strong leadership and incentives provided by the organisation, [13,22,23] and iii) developing strong partnerships between researchers and managers. $[19,24,25]$

\section{Limitations of the study}

This study focused on mid-level HSMs at two local hospitals. Participants were volunteers, thus not randomly selected. The sample size was small, but enough to detect significant differences between the assessment types and between the two hospitals. Lessons learnt from the study need to investigated in more detail in a larger and more diverse population.

\section{Conclusion}

Using a $360^{\circ}$ subjective assessment and a case studybased objective assessment, the competence of mid-level managers from two Victorian hospitals in demonstrating the competency of EIDM was assessed. The assessment confirmed that the mid-level managers are competent, with areas requiring guidance and improvement in order to enhance their competence. The study also confirmed that 
the areas requiring improvement in the EIDM practice varied between organisations and individual managers. The study supports the evidence that improving the competence of individual manager is important to enhancing the EIDM practice. However, such improvement cannot be achieved on a large and wide scale without a combination of efforts at system, healthcare organisation and individual management levels.

As a first step towards improving EIDM practice amongst health service managers, the identification and confirmation of individual managers' competence in applying the competency of EIDM in their roles and areas within the EIDM practice that require improvement are necessary. To improve EIDM in management practice, targeted strategies should be developed for managers from individual organisations and sector-wide. With other key influential factors to EIDM practice being addressed, significant improvement in EIDM amongst the health service management workforce may be achieved - a practice leading to better decision outcomes and ultimate improvement of the effectiveness and efficiency in health service provision.

\section{Acknowledgements}

We thank all the participants of the competency assessment and the support and funding from the project partners Victorian Healthcare Association, The Australian College of Health Services Management, and the Sector Workforce Planning, Victorian Department of Health. We also thank members of the project Advisory Committee and are grateful for the financial contribution from 14 Victorian Health Services.

\section{Competing Interests}

The authors declare that they have no competing interests.

\section{References}

1. Walston S, Khaliq A. The importance and use of continuing education: findings of a National Survey of hospital executives. J Health Adm Educ. 2010;(Spring):113-125.

2. Cookson R. Evidence-based policy making in health care: what it is and what it isn't. J Health Serv Res Policy. 2005;13(3):118-121.

3. Liang Z, Leggat S, Howard P, Koh L. What makes a hospital manager competent at the middle and senior levels? Aust Health Rev. 2013;37:566-573.

4. Liang Z, Howard P, Leggat S. $360^{\circ}$ Management Competency Assessment: is our understanding adequate? Asia Pacific Journal of Human Resources (online since 2016,12 February).

5. Lomas J, Culyer T, McCutcheon C, McAuley L, Law S. Conceptualizing and combining evidence for health system guidance. Ottawa: Canadian Health Services Research Foundation; 2005.

6. Howard P, Liang Z, Fitzgerald L. Evidence-based decision making in health service management: the knowledge and practice amongst middle to senior level health service managers in Victoria, Australia. Saarbuecken:VDM; 2009.
7. Birdsell JR, Thornley R, Landry C, Eastabrooks, Mayan M. The utilization of health research results in Alberta. Edmonton: Alberta Heritage Foundation for Medical Research; 2005.

8. Liang Z, Howard P, Leggat S, Murphy G. A framework to improve evidence-informed decision-making in health service management. Aust Health Rev. 2012; 37:566-573.

9. Liang Z, Howard P, Rasa J. Evidence-informed managerial decisionmaking - what evidence counts? (Part-one). Asia Pac J Health Manage. 2011;6(1):232-229.

10. Liang Z, Howard P. Evidence-informed managerial decision-making - what evidence counts? (part two). Asia Pac J Health Manage. 2011; 6(2):12-21.

11. Kovner A, Rundall T. Evidence based management reconsidered. Front Health Serv Manage. Front Health Serv Manage. 2006; 22(3):3-22.

12. Maurer J, Kimberly A, Haefner J, Stuart A, William C. Beliefs about 'improvability' of career-relevant skills: relevance to job/task analysis, competency modelling, and learning orientation. Journal of Organisation Behaviour. 2003;24(107-131).

13. Shortell S. Promoting evidence-based management. 2006. Front Health Serv Manage. 2006;22(3):23-29.

14. Hewison A. Evidence-based management in the NHS: Is it possible? J Health Organ Manage. 2004;18(5):336-348

15. Stefl M. Common competencies for all healthcare managers: the healthcare leadership alliance model. J Healthc Manage. 2008; 53(6):14.

16. Garman A, Tyler J,Darnall J. Development and validation of a 360 -degree-feedback instrument for healthcare administrators. J Healthc Manage. 2004;49(5):307-321.

17. McCarthy G, Fitzpatrick J. Development of competency framework for nurse managers in Ireland. J Contin Educ Nurs. 2009;40(8): 346-350.

18. Epstein R, Hundert E. Defining and assessing professional competence. JAMA. 2002;287(2):10.

19. Dobbins M, Cockerill R, Barnsley J. Factors affecting the utilization of systematic reviews: a study of public health decision makers. International Journal of Technological Assessment in Health Care. 2001;17(2):203-214.

20. Cohen $D$. The very separate worlds of academic and practitioner publications in human resource management: reasons for the divide and concrete solutions for bridging the gap. Academy Management. 2007;50(5):1013-1019.

21. Rynes S, Giluk T, Brown K. The very separate worlds of academic and practitioner periodicals in human resource management: implications for evidence-based management. Journal of Academic Management. 2007;50(5):987-1008.

22. Nutley S, Davies H. Making a reality of evidence-based practice: some lessons from the diffusion of innovation. Public Money and Management. 2000; (October-December ): 35-42.

23. Adily A, Ward J. Enhancing evidence-based practice in population health: staff views, barriers and strategies for change. Aust Health Rev. 2005;29(4):469-477.

24. Golden-Biddle K, Reay T, Petz S, Witt C, Casebeer A, Pablo A, et al. Toward a communicative perspective of collaborating in research: the case of the researcherdecision-maker partnership. J Health Serv Res Policy. 2003;8(2):20-25.

25. Ross S, Lavis J, Rodriguez C, Woodside J, Denis J. Partnership experiences: involving decision-makers in the research process. J Health Serv Res Policy. 2003;8(S2):26-34. 
Appendix 1: 12 behavioural items for evidenceinformed decision-making (selfassessment)

1. Use timely and appropriate questioning/investigation to identify the nature of problem, issue or opportunity.

2. Seek appropriate evidence from multiple organisational sources to guide the identification of solutions.

3. Seek appropriate (qualitative/quantitative) evidence from multiple external sources to guide the identification of solutions.

4. Critically appraise the validity and relevance of evidence.

5. Assesse and prioritise the relevance of the evidence to the question(s).

6. Actively use evidence to question and improve existing practice and process.

7. Apply the best form(s) of evidence to guide management decision-making.

8. Evaluate the process of searching for and applying evidence to management decisionmaking.

9. Anticipate decision implementation problems/impacts and develops and communicate appropriate contingency plans.

10. Set measures and use them to evaluate the outcomes of decisions.

11. Encourage and support colleagues and subordinates to use evidence to guide decisionmaking.

12. Anticipate and prepare for the future by staying abreast of best practice and emerging trends that will have an impact on health outcomes. 